\title{
Recent Advances in Techniques for Flavor Recovery in Liquid Food Processing
}

\author{
Shima Saffarionpour ${ }^{1} \cdot$ Marcel Ottens ${ }^{1}$
}

Received: 29 March 2017 / Accepted: 2 October 2017 / Published online: 15 November 2017

(C) The Author(s) 2017. This article is an open access publication

\begin{abstract}
Recovery of volatile flavor-active aroma compounds which are key components of processed liquid food streams is of utmost concern to food industry, as these compounds contribute to the quality of the final product. This review paper highlights the recently published research on different techniques that can be applied for recovery of the key flavor components which all aim for minimizing the loss of volatile aromas and (re-) using them in process streams, in order to enhance the flavor profile of the liquid food product. Among the available techniques for flavor recovery in food industry, distillation or stripping, pervaporation, supercritical fluid extraction, and adsorption showed potential for selective recovery of the flavor components from liquid food streams. These techniques can be combined in different stages of the process or applied as an alternative to the other techniques for aroma recovery. Less attention has been paid to supercritical fluid extraction among the available techniques, especially for recovery of aroma components from alcoholic beverages. Since this technology demonstrated high selectivity for flavor recovery in fruit juices and can take profit from applying natural solvents like $\mathrm{CO}_{2}$, further research on the application of this technology combined with counter-current flow in a multi-stage contactor is recommended to optimize the recovery process. Adsorption also shows potential for flavor recovery that can be combined with thermal processing or applied as an alternative standalone technique.
\end{abstract}

Marcel Ottens

m.ottens@tudelft.nl

1 Department of Biotechnology, Delft University of Technology, Van der Maasweg 9, 2629, HZ Delft, The Netherlands
Keywords Volatile flavor components · Selective recovery Liquid food streams $\cdot$ Alternative techniques

\section{Introduction}

Flavor perception is the sensory impression of food or any other chemical substance, determined by chemical senses of taste and smell [81]. Flavors are a mixture of volatile aroma compounds which are classified to natural, natural identical, and artificial flavorings, [13, 37, 53, 96]. Different chemical substances contribute to particular flavor perceptions [37, 55] as is depicted in Fig. 1. Flavor-active compounds, which are normally present in beverages and liquid foods, are various organic compounds, typically present at low concentrations (ppm levels). Different classes of these organic compounds, which can be regarded as aromas, for instance, are aldehydes [36, 55, 95], esters [23, 57, 106], carboxylic acids [27, 98], phenols [26, 49, 91, 110], hydrocarbons [76], ketones [34], and terpenes [31,54]. These flavor-active components are widely used in beverage industry with the largest market in North America, followed by Asia-pacific and Europe [59]. These markets are highly mature and emerging in Latin America and Eastern countries. Approximately a growth rate of $5 \%$ is projected to food flavor market since 2015 and continuous growth is expected till 2020 [60].

The value of food flavor market is projected to reach USD 15.1 billion by $2020[6,60]$. Several alcoholic drinks such as wine, beer, cider, and spirits are available in the market, in which global top players account for share above $60 \%$. Flavored alcoholic beverages (FABs) share an important market segment based on different age groups and beer, cider, and FABs dominated the global market in 2014 [10]. Considering the growing demand for flavor-active components' consumption in food and beverage industry, it is of extreme importance 


\section{Natural flavorings}

* From plant or animal raw material

Isolated by physical methods.

* Obtained from microbial or enzymatic processes.

\section{Artificial flavorings}

* Not intended yet in a natural product

Typically produced by fractional distillation and additional chemical manipulation.

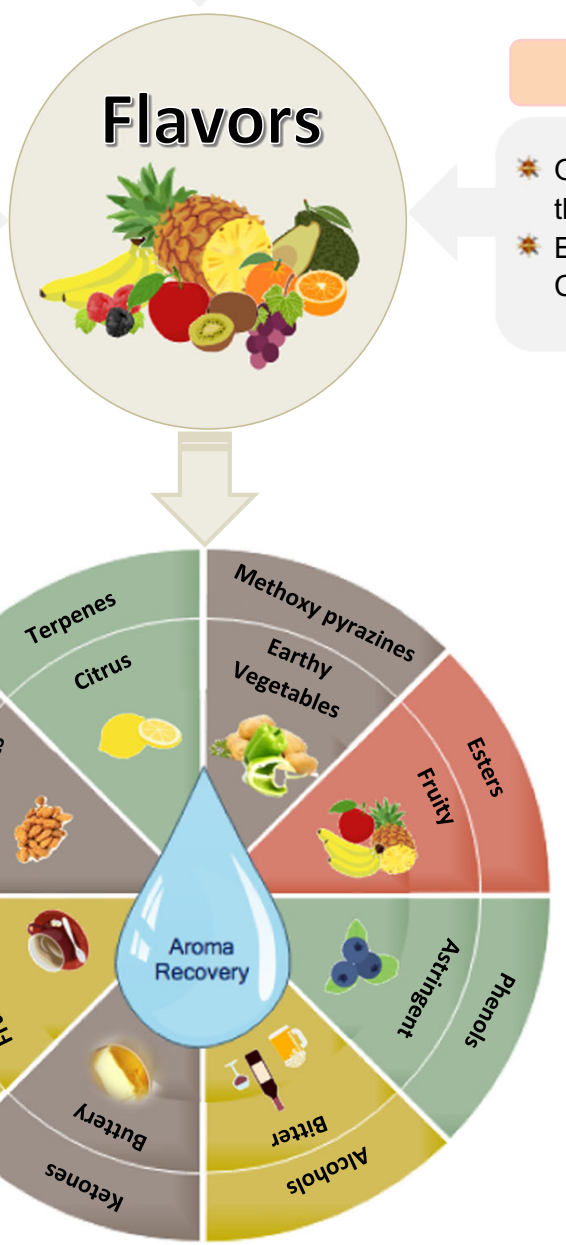

Natural-identical flavorings

Obtained by synthesis or isolated through chemical processes.

* E.g. Vanillin from lignin Citral obtained by chemical synthesis

Fig. 1 Classifications of flavors in food and beverages and contribution of chemical compounds to various flavors [13, 40]

to quantify and control the level of these compounds accurately. The main flavor-active compounds present in liquid foods and beverages together with their physical properties (hydrophobicity and solubility) are presented in Fig. 2. The functional groups (groups responsible for chemical reactions) for each molecule are illustrated in red color. The higher value of partition coefficient indicates more hydrophobicity of the flavor compound and less solubility in water can be achieved [75].

During processing, the flavor composition of the beverage might alter to a great extent, due to chemical and physical changes of the aroma complex [52]. Chemical changes might occur due to oxidations or Maillard reactions [67], during heat treatment that can result in losses of the flavor compounds or formation of new flavor compounds from original flavors. Physical changes in the flavor composition can also occur during concentration and removal of the excess water, while some amounts of the volatile flavor compounds like esters might be lost due to evaporation. These changes in flavor composition are considered as undesired, and in order to prevent or reduce the unwanted changes in composition of flavors, different techniques can be implemented, which take advantage of the physical properties of flavor-active components like solubility, relative volatility, and hydrophobicity for their separation (as explained in Fig. 3). To reduce the 


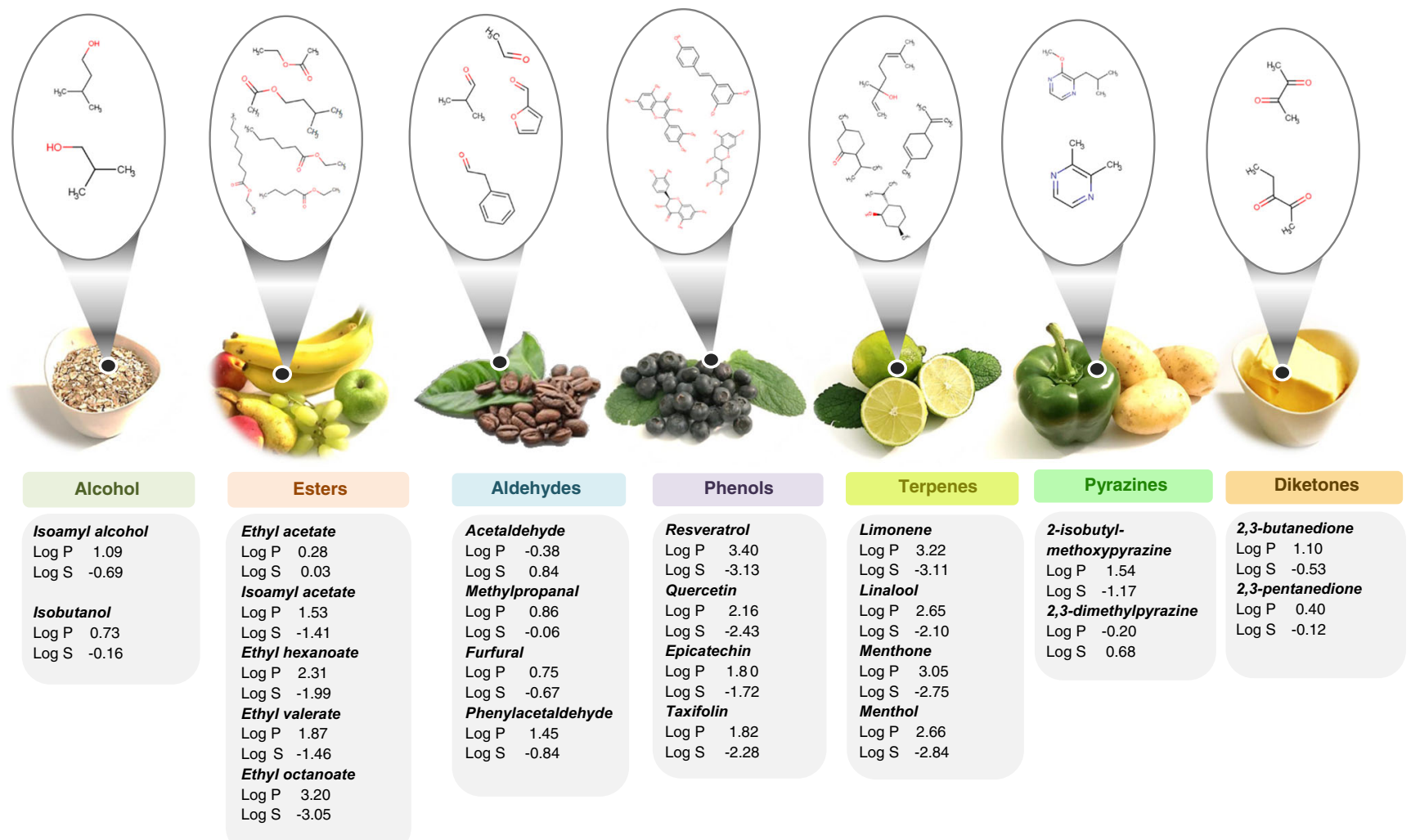

Fig. 2 Main flavor-active components in liquid foods and their physical properties (Hydrophobicity and solubility) (ChemAxon) [20]. The Partition coefficient $(\mathrm{P})$ is the ratio of concentrations of an un-ionized compound in the two phases of immiscible solvents (water and $\mathrm{n}$-octanol) at equilibrium. $\log \mathrm{P}$ is the 10 -base logarithmic measure of the partition coefficient; $\log \mathrm{S}$ or intrinsic solubility is the 10-base logarithmic measure of the solubility (mol/L)

liquid food streams and is usually connected with evaporation $[79,101,108]$. It is mainly performed by stripping or distillation processes (based on differences in components' relative volatility) and also other alternatives like pervaporation (using vapor and liquid phase and a membrane), supercritical fluid extraction (using liquid/ solid and a supercritical fluid), and adsorption (using solid as auxiliary phase and liquid). Fig. 3 represents the available technologies for aroma recovery in liquid food processing. An overview of current research advances in each technology is provided in the next sections.

\section{Aroma Recovery Through Distillation}

The principle of the classical distillation system is stripping the aqueous food stream containing the most volatile compounds and concentrate them by fractional distillation to a solution about 100-200 times the original concentration [86]. It usually combines stripping with rectifying and enrichment of the volatile aroma compounds [61] (represented in Fig. 3 (part $\boldsymbol{a}$ )), in which the former depends on the relative volatility of the aroma components. An impressive number of research works contribute to our understanding of the application of this technology for flavor recovery from liquid food processing of fruit juices, alcoholic beverages, and other 


\section{Alternative technologies for flavor recovery}

a Separation technology based on vapor/liquid equilibrium
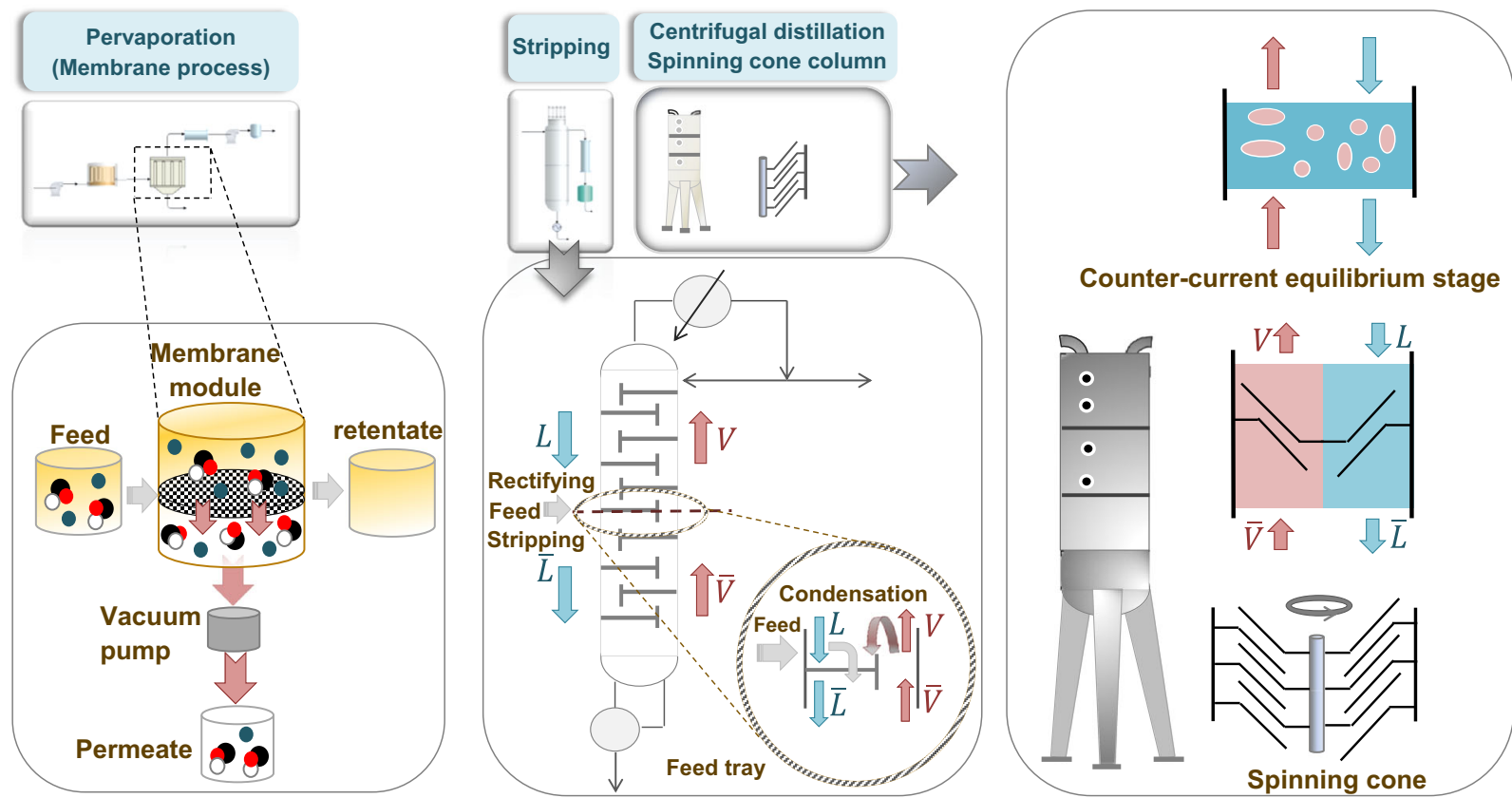

b Separation technology based on liquid/solid and supercritical fluid equilibrium
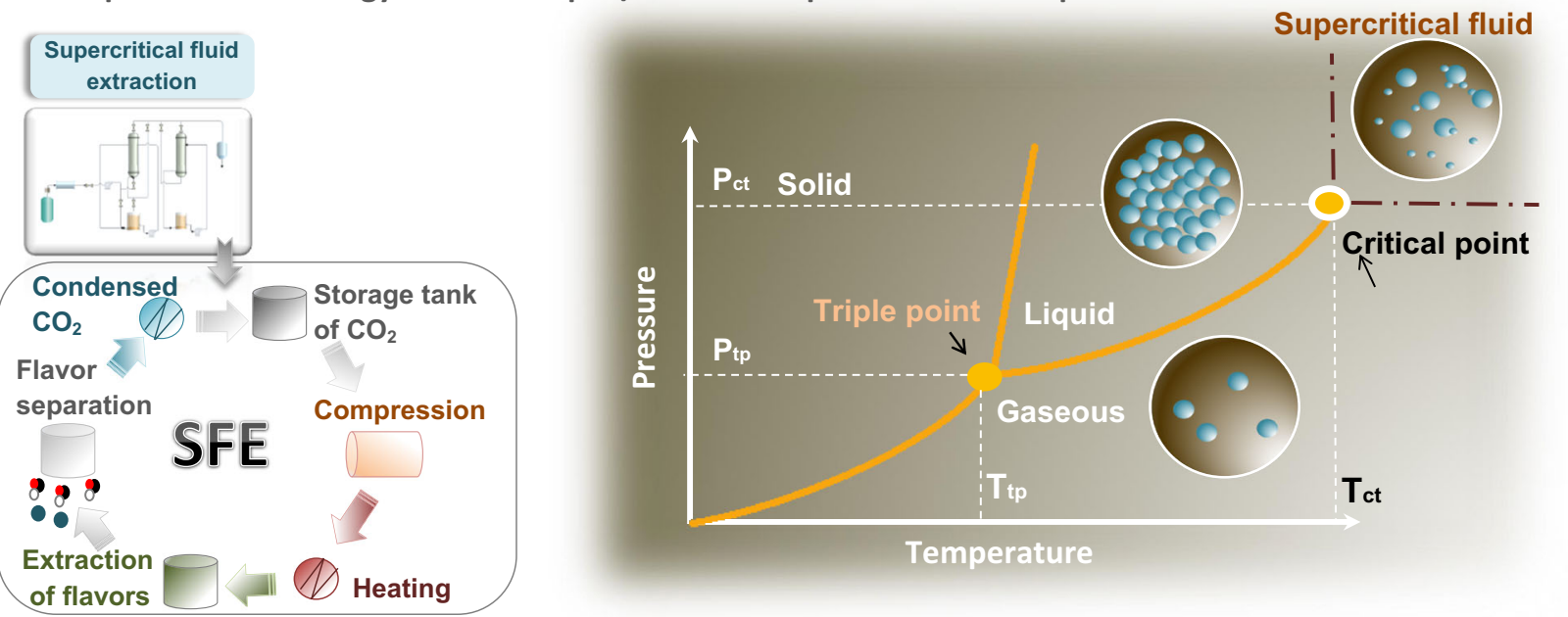

C Separation technology based on solid/liquid equilibrium

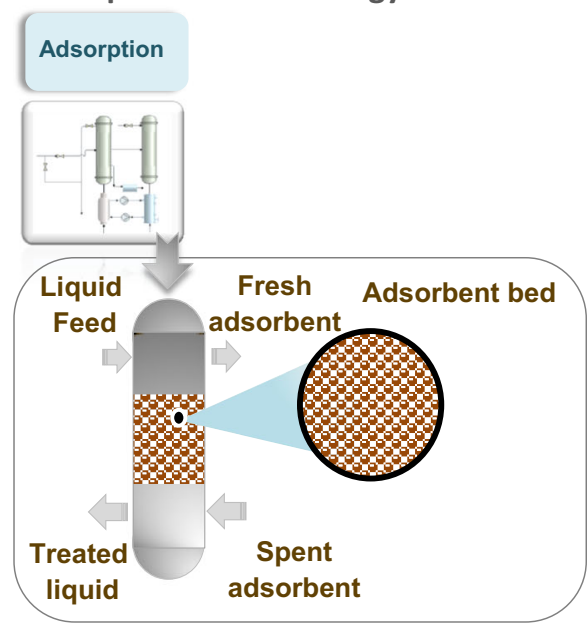

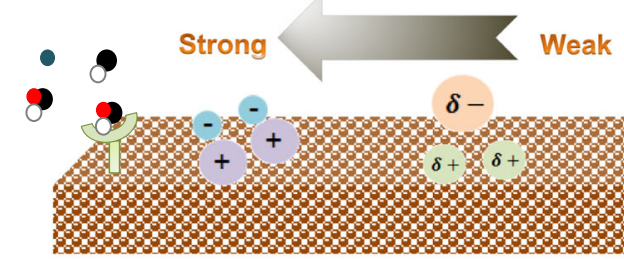

Affinity Ion exchange Adsorption Adsorption adsorption adsorption (IEC) polarity Hydrophobicity
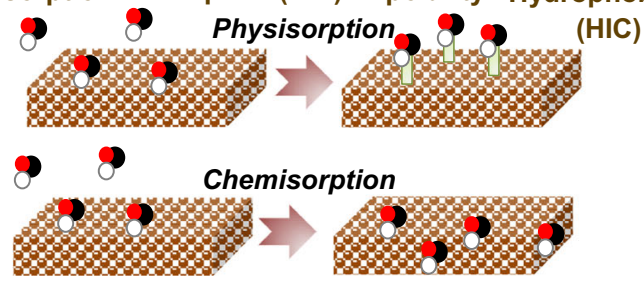
4 Fig. 3 Alternative technologies for flavor recovery: a vapor/liquid equilibrium (pervaporation, stripping, and centrifugal distillation), b liquid/solid and supercritical fluid equilibrium (supercritical fluid extraction), and $\mathbf{c}$ solid/liquid equilibrium (adsorption) [24, 71, 88]

and beverages $[4,5,21,33,35,38,45,63,66,68,89,93,94$, 99]. Few recent research works unequivocally demonstrated the application of Membrane Distillation (MD) and Vacuum Membrane Distillation (VMD) for flavor recovery during the last 4 years $[1,21,68,77]$. Performance of MD is investigated during beer dealcoholization processing and the effect of feed and vacuum pressure are investigated on flux and selectivity of a thin-film composite polyamide membrane. The increase of feed and vacuum pressure could improve the membrane flux, but decreased the membrane selectivity [77] and no major change in composition of the flavor components, maltose, and glycerol was observed, only slight loss of maltose in dealcoholized beer was related to the adsorption phenomena on the membrane surface for which membrane flushing for recovery of the flavor compound was proposed. In comparison to MD configurations, VMD is believed to be an attractive and cost-competitive technology, besides being characterized by a lower operating temperature and hydrostatic pressure. It permits higher partial pressure gradients; therefore, higher permeate flux can be achieved [1, 35, 99].

The application of this technology is investigated recently for fractionation and separation of hydrocarbon terpenes of green mandarin from alcohols, ketones, and aldehydes [93].

The influence of column pressure on boiling point of essential oil and the composition of compounds in distillate is studied. According to this study, efficient separation of terpenes could not be achieved unless higher number of stages are used and no major degradation of distillate and bottom streams was observed, with no effect on the quality of the final product [93]. In the other studies, different operating strategies like variable reflux rate are explored to increase the level of terpenic compounds in specific wine distillate fractions to emphasize on floral aroma [63]. A drastic reduction of internal reflux could enhance the recovery of terpenic compounds, while producing a distillate which is rich in floral aromas, and reduction in cooling flow could increase the presence of higher alcohols and esters. The application of MD is compared with VMD, for comparison of volatile composition of wine fractions by two different dealcoholization techniques, i.e., using a membrane contactor (MC) and distillation under vacuum (D). The main difference observed between the two techniques was the concentration grade reached by the dealcoholized fractions which was 5 to 6 times higher when applying VMD, due to associated loss of water [66]. The result obtained was in agreement with previous observations reported in other research works [38]. Recent study, conducted by [89], is concerned with foaming, the main problem associated with stripping which might occur due to formation of gas bubbles in the liquid and their stabilization through adsorption of surface active agents at their interface. They have studied the application of this technology for fruit juice processing, with the main focus on studying the feasibility of air stripping implementation, using a bubble column for recovery of the flavor components. The summary of the recent research works on application of distillation/stripping technique for flavor recovery in processing liquid foods is assembled in Table 1.

\section{Aroma Recovery Through Centrifugal Distillation}

Distillation can be performed in a spinning cone column (SCC), a technology developed by Conetech [24], for recovery of aromas and removing undesirable volatile components from fruit juices and other food liquid streams (see Fig. 3 (part a)). This technology has the advantage that it operates at low temperatures, short residence times, with effective vapor/ liquid mixing. Counter-current contacting the vapor and the liquid in alternating and rotating truncated cones which act as contacting stages increases the mass transfer rates and has the advantage over conventional plate columns, operating at atmospheric pressure, since separation efficiency about 20NTU/ $\mathrm{m}$, can be achieved in SCC in comparison to $6 \mathrm{NTU} / \mathrm{m}$ in packed columns [86]. It has been successfully applied for recovery of volatile aroma compounds in wine and beer industry, for removing delicate aromas, removal of sulfur dioxide from grape juice, production of grape concentrates and alcohol reduction in wines $[19,58,88]$. A number of comparative studies are available on the application of this technology for aroma recovery for liquid foods. Table 1 highlights the most recent research conducted on the application of this technology.

\section{Pervaporation Membrane Separation Technique}

Pervaporation is an attractive technology for processing thermal sensitive aroma compounds. This membrane process is based on a selective transport of a liquid mixture through a selective ceramic or polymeric membrane [2] (as illustrated in Fig. 3, part $\boldsymbol{a}$ ). This technique can be an alternative to conventional separation processes such as steam distillation, liquid solvent extraction, and vacuum distillation and has been successfully applied during the last years, for recovery of aroma compounds from fruits and fruit juices $[11,39,47,70,73,78]$ and subsequent addition to the same juice after concentration by evaporation $[41,51,92]$. Pervaporation technique has also been applied for ethanol removal over the last few years [18, $97,102]$ and aroma recovery from alcoholic beverages [14, $17,19,50]$. The most recent studies for the application of this technique, conducted by different researchers in food industry, are summarized in Table 1.

In the recent studies conducted by Catarino et al. [17] and Catarino and Mendes [18] on aroma recovery from beer and 


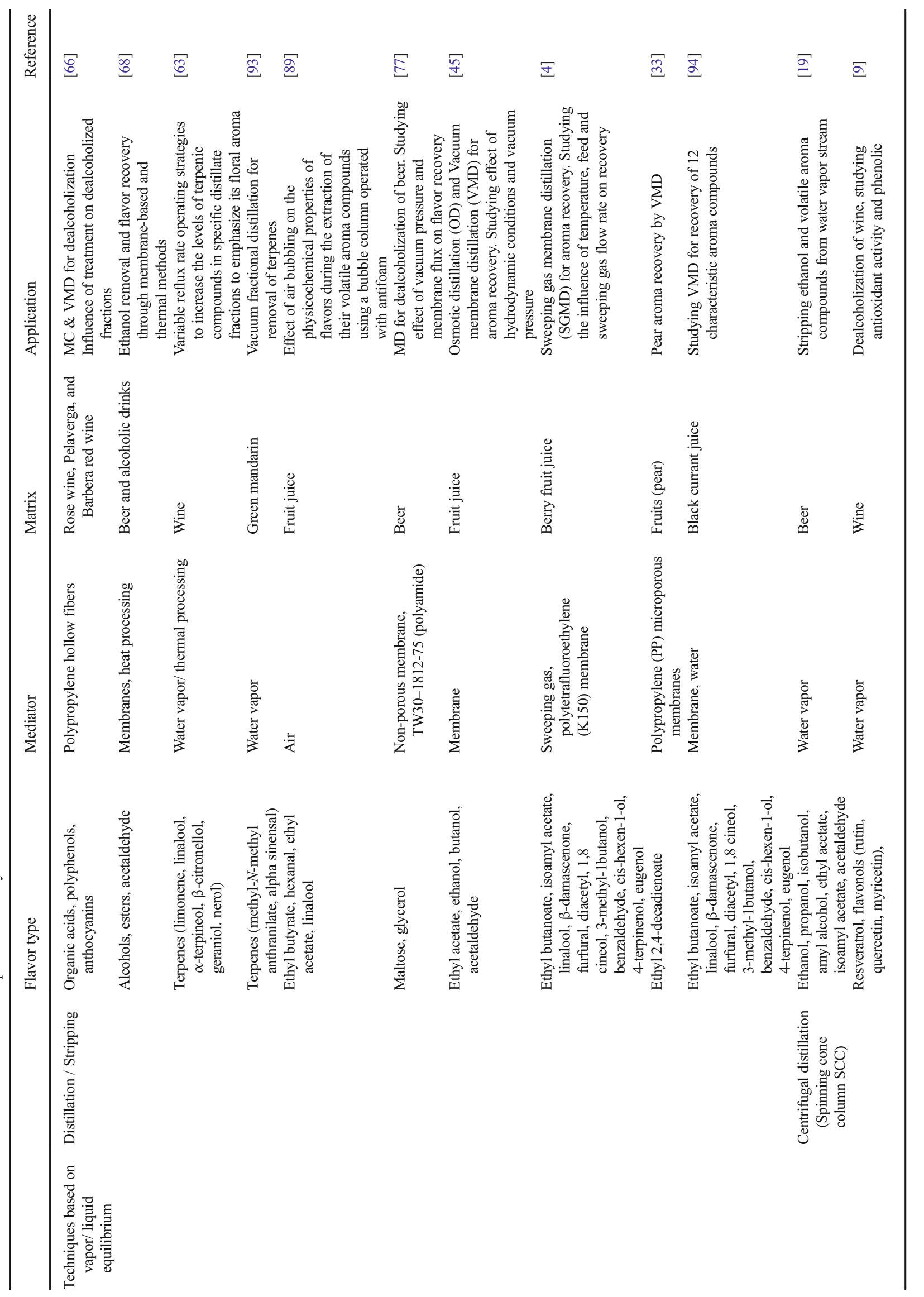




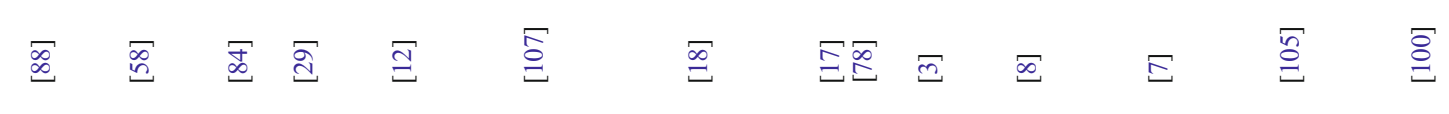

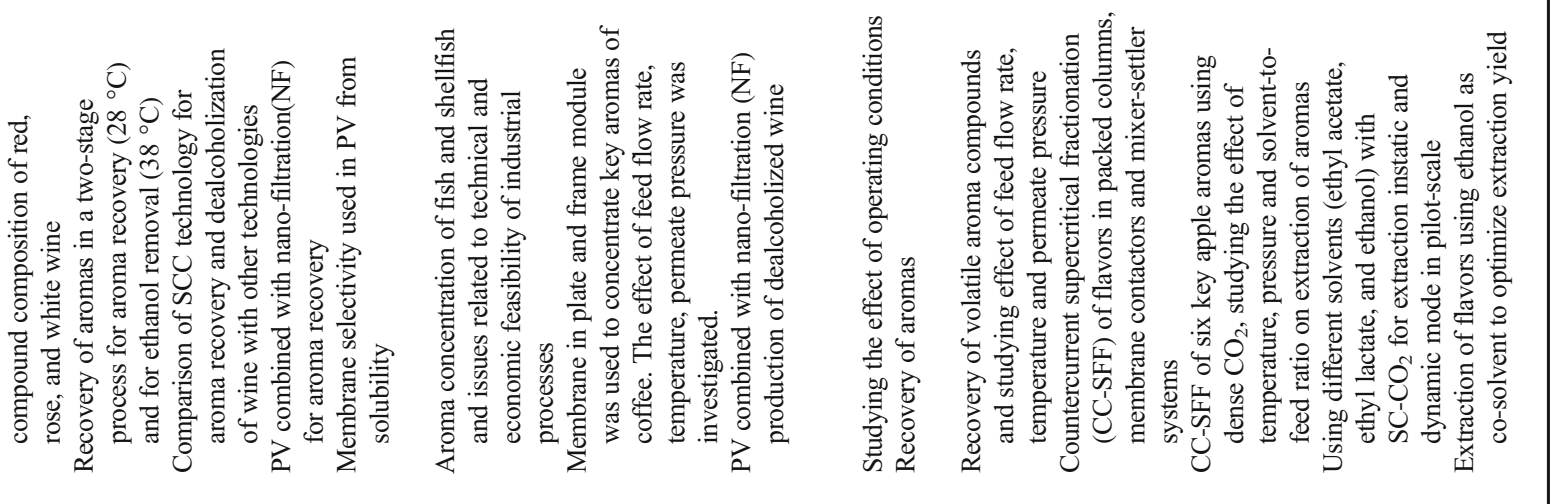

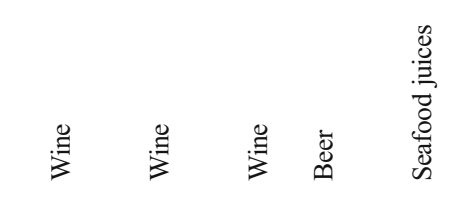

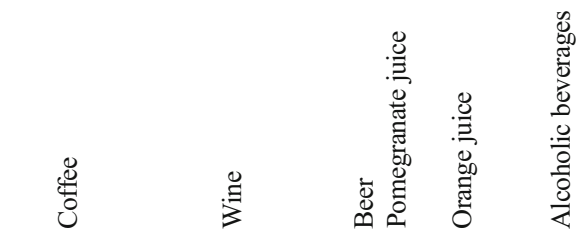<smiles>C[C@H]1C[C@H](C)C1</smiles>

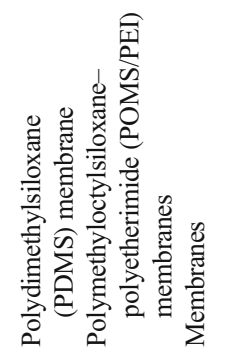<smiles>C[C@H]1C[C@@H]1C[C@H]1C[C@H]1C</smiles>

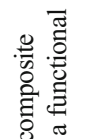
空言事

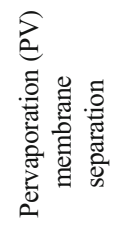




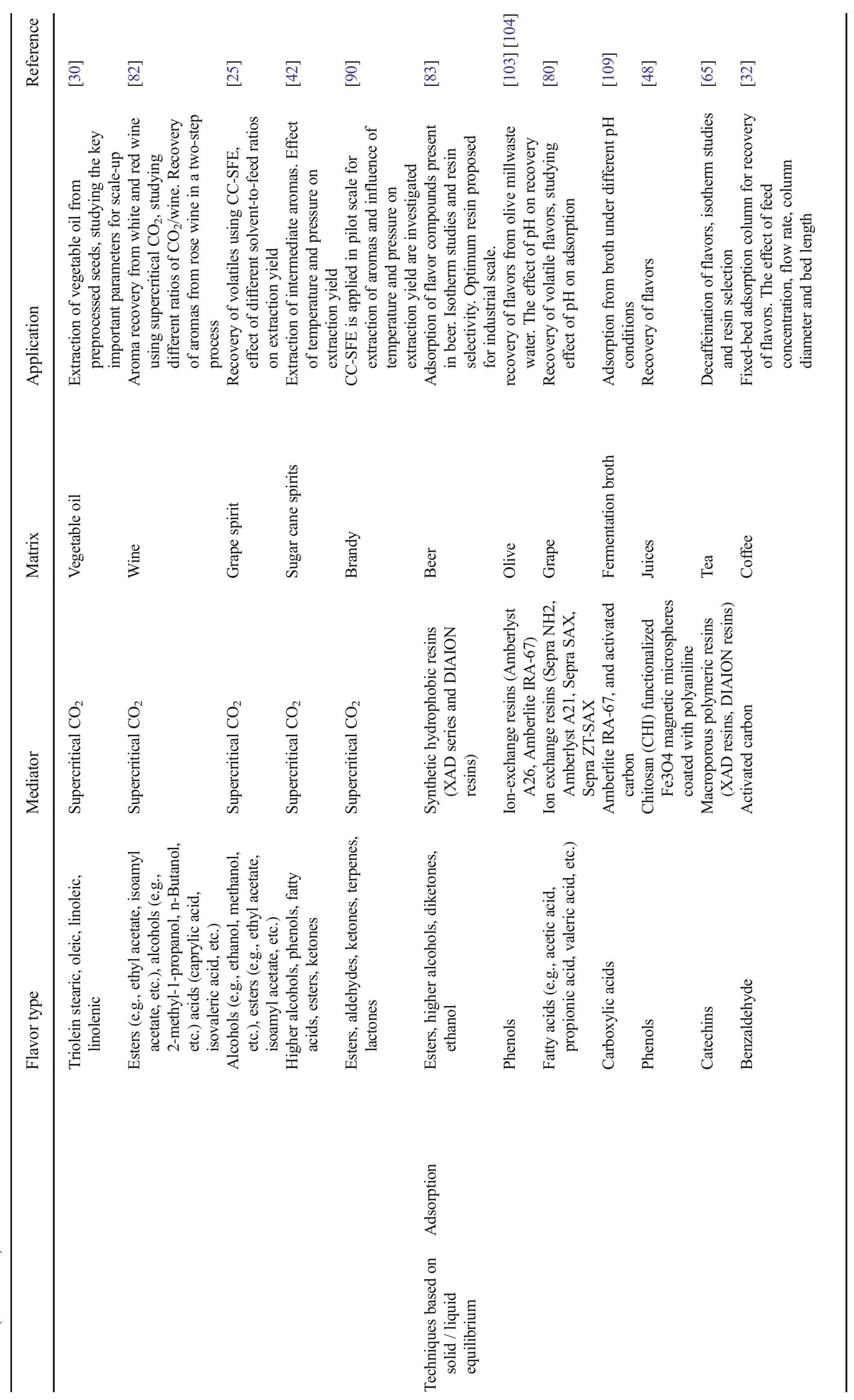


wine, the effect of operating conditions such as feed velocity and temperature and permeate pressure are studied on process performance, considering the responses of permeate flux and aromas/ethanol selectivities, ethanol concentration and ratio between higher alcohols and esters in the permeate. They proposed the optimum operating conditions and the range of selectivities for higher alcohols and esters: four alcohols (ethanol, propanol, isobutanol, and isoamyl alcohol), two esters (ethyl acetate and isoamyl acetate) and an aldehyde (acetaldehyde). According to their studies on lab scale, selectivity of higher alcohols was positively affected by the temperature and to a minor extent by the feed velocity, while permeate pressure affects negatively their selectivity due to their low saturated vapor pressures (low volatilities) $[17,56]$. This trend was not observed on industrial plant scale. On the other hand, selectivity of esters decreased with temperature and increased with permeate pressure and velocity. As a result, the ratio of higher alcohols/esters increased with the temperature and decreased with feed velocity and permeate pressure. A new industrial process was proposed in further studies for producing nonalcoholic beer $[17,18]$. The aroma compounds are obtained by pervaporation of the original beer using the same composite membrane, which they had tested in order to investigate the effect of operating conditions in their previous studies. High permeation temperature and low feed flow rate were the most effective for maximizing the permeation flux and the equilibrium of the flavor profile. For production of dealcoholized wine, they could also successfully combine pervaporation with nano-filtration (NF) for recovery of aroma compounds before the dealcoholization step and adding the recovered aromas back again to the dealcoholized product, which increased the flavor sensation. The application of pervaporation with NF is investigated by Catarino and Mendez [18] and Salgado et al. [84] for recovery of aromas from low-alcohol white wines. They have investigated the performance of the combined units in pilot scale for recovery of aroma components. A two-stage NF process was tested for sugar reduction of must, followed by pervaporation to recover aroma precursors from grape must (i.e., higher alcohols and esters) and restitution of the flavor precursors. They could achieve the best results for obtaining an optimal aroma profile close to original must, by combining pervaporation with a two stage NF. To achieve more desirable results, they proposed the enhancement of mass transfer during pervaporation through increasing the pervaporation time, a higher feed tangential flow or feed pressure which improves the aroma transfer, taking into account the limit for maximum pressure drop. In the other studies conducted by Del Olmo et al. [29], the final quality of the alcohol-free beer was improved through pervaporation to recover the aromas and flavor constituents of beer, such as isobutyl alcohol, ethyl acetate, and isoamyl acetate. The application of pervaporation concentrating volatile aroma compounds in industrial soluble coffee is studied in the research work conducted by Weschenfelder et al. [107]. They have investigated the effect of feed flow rate, temperature, and permeate pressure on the pervaporation performance of selected compounds in the group of ketones (i.e., 2,3-butanedione and 2,3-pentanedione), aldehydes (i.e., benzaldehyde, and acetaldehyde and furfural and 5-methyl-furfural), and alcohols (i.e., 3-methyl-butanal) and 2,5-dimethylpirazene. For all the tested compounds, permeation flux increased with temperature and results indicated that aroma compound fluxes decreased with partial pressure except for 5-methyl-furfural, and 2,3butanedione and 2,5-dimethyl pirazene presented the highest enrichment factors in the experimental conditions evaluated in their work. They proposed an optimization step for industrial purposes in order to concentrate the aroma profile for soluble coffee. More information on the current state of research on application of this technology for flavor recovery is given in Table 1.

\section{Aroma Recovery Through Supercritical Fluid Extraction}

Supercritical fluid extraction (SFE) is a process which uses substances at pressure and temperature above the critical point (as illustrated in Fig. 3 (part $\boldsymbol{b}$ )) as solvents to extract valuable materials $[7,28,85]$. Supercritical extraction with $\mathrm{CO}_{2}$ has been widely adopted for isolation of volatile aroma compounds in plants and fruits $[7,42,100]$ and vegetable oils from preprocessed seeds $[30,69]$. There are some research works concerned with aroma recovery from alcoholic beverages [90] combined with a dealcoholization process $[15,64,82]$. Supercritical $\mathrm{CO}_{2}$ can be applied for batch extraction of solids, for multi-stage counter-current separation and fractionation of liquids, and for adsorptive and chromatographic separations $[15,62]$. This technique is mainly carried out at different modes of operation, which is mainly concerned with extraction from solids, carried out in batch or single-stage mode. Single-stage extraction consists of two process steps, extraction and separation of the extract from the solvent. This simple mode of operation enables contacting the feed until a certain mean residual concentration in the solid raffinate is achieved. However, during the extraction process, many factors like extraction kinetics might change due to depletion of the solid substrate from solid that might change the optimum process conditions. In addition, loading the solvents can be enhanced by increasing the number of stages and operating in a countercurrent mode. This alteration reduces the amount of solvent required and makes continuous production of extract achievable [15]. Application of counter-current supercritical extraction was studied for apple aroma recovery by Bejarano and Del Valle [7]; the effect of temperature, pressure, and solvent to feed ratio on fractionation and concentration characteristics of six apple aromas is investigated. They could achieve high separation of individual aromas over water, extraction yield of aromas higher than $86 \%$. However, polarity difference 
between the tested compounds was the drawback of application of this technique for separation of some tested alcohols from aldehydes. The other recent research work is concerned with extraction of catechins and caffeine from green tea, using different co-solvents (i.e., ethyl lactate, ethyl acetate, and ethanol) and supercritical $\mathrm{CO}_{2}\left(\mathrm{SC}-\mathrm{CO}_{2}\right)$ [105]. For the experimental procedure, two different approaches of static (introducing the co-solvent in the extraction cell and pumping $\mathrm{SC}-\mathrm{CO}_{2}$ ) and dynamic (mixing co-solvent with $\mathrm{SC}-\mathrm{CO}_{2}$ before introduction into the extraction cell) were tested in pilot scale. The highest caffeine extraction yield was obtained with ethyl acetate using both approaches (13 and $14.2 \mathrm{mg} \mathrm{g}^{-1}$ of tea), followed by ethanol $\left(10.8\right.$ and $\left.8.8 \mathrm{mg} \mathrm{g}^{-1}\right)$. Lowest extraction yield was achieved using ethyl acetate as co-solvent (lower than $7 \mathrm{mg} \mathrm{g}^{-1}$ ). Application of ethanol as a co-solvent in extraction of flavors using $\mathrm{SC}-\mathrm{CO}_{2}$ is also investigated for extraction of fatty acid esters, phenols, coumarin, and terpene derivatives from citrus [100]. The most enriched and concentrated extracts of coumarin (osthole) was obtained (approximately $47 \%$ ) at 170 bar. Furthermore, SCE is successfully applied for flavor recovery and ethanol removal from alcoholic beverages $[25,42,82,90]$. In the studies conducted by Ruiz-Rodriguez et al. [82], this technique is implemented for aroma recovery and ethanol removal from aqueous solutions. They have developed a two-step process for production of low-alcohol beverage from wine by recovering the aromas in a counter-current packed column using low $\mathrm{CO}_{2}$ /wine ratios. The developed two-step process proved to have similar antioxidant activities and aroma profile to the original wine. Recovery of volatile alcohols and esters is investigated on pilot scale using counter-current supercritical fluid extraction (CC-SFE) from grape spirits [25]. The effect of different solvent-to-feed ratios is examined on recovery of volatiles. As they concluded in their survey, in order to achieve the highest ethanol and volatiles' extraction yield, lowest solvent-to-feed ratio should be used.

$\mathrm{SC}-\mathrm{CO}_{2}$ extraction was employed for extraction of aroma compounds from sugar cane in the work of Gracia et al. [42], for rum production. According to their studies, the extraction yield increased with increasing the temperature and pressure. Optimization of counter-current supercritical fluidic extraction (CC-SFE) conditions is explored by Señoráns et al. [90] for obtaining high-quality brandy aromas. As is demonstrated in their work, increasing the flow rate increased the presence of aroma compounds in the separator. When increasing the extraction pressure, a higher sample flow rate has to be used to achieve the maximum extraction.

Supercritical $\mathrm{CO}_{2}$ technology is adopted widely and its economic feasibility and advantages over conventional techniques should be proven for each applied technology. Despite initial high capital costs, operating costs would be lower, as it is operated as a continuous process $[62,74,82]$, and overall feasibility can be proven at certain scales of operation. This technology enables the possibility of combining an extraction operation with column fractionation under supercritical conditions to concentrate the bioactive flavor components [62]. In comparison to other techniques for aroma recovery, less attention has been paid to application of this technology for recovery of aroma compounds from liquid food streams. Further studies on application of this technique for aroma recovery is recommended, especially for production of alcoholic beverages, which is of high economic interest [10].

\section{Regeneration and Recovery of Aromas via Adsorption}

Among the available techniques for aroma recovery, adsorption is a technique which shows potential for selective recovery of the flavor compounds and can be applied as an alternative to thermal processes or can be combined with distillation/ stripping in an integrated process $[22,46,72]$. It can be applied as a technique for selective recovery of the compounds based on their affinity toward a ligand (affinity chromatography), based on charge (ion-exchange chromatography), hydrophobicity (hydrophobic interaction chromatography (HIC)), and based on polarity, or size of the molecules (size exclusion chromatography (SEC)) [43, 44, 87]. The mechanism of different modes of separation in adsorption technique is depicted in Fig. 3 (part $c$ ). During the last 2 years, this technique has been successfully applied to recover mainly phenolic compounds besides other volatile aroma components from liquid streams in food processing industry using adsorbents such as activated carbon, chitosan, minerals (zeolites), and synthetic resins $[16,32,48,65,83,103,104,108]$. In the recent studies, application of this technique is investigated for recovery of coffee aroma compound benzaldehyde on granular activated carbon derived from coconut husk [32]. The effect of fixed-bed operating parameters like inlet concentration and inner diameter of the bed are investigated on adsorption and recovery of the aroma component. They could use the obtained results from column performance to perform a scale-up study with error of less than $12 \%$. The current research focus is on development of this technique to synthesize new adsorbent materials which have more affinity to adsorb aroma components [48]. The application of synthesized chitosan, functionalized with $\mathrm{Fe}_{3} \mathrm{O}_{4}$ magnetic microspheres coated with polyaniline, is studied for adsorption of phenolic components in juice samples. According to the obtained results, synthetic microspheres showed high permeability and acceptable recovery of the phenolic components (between 85 and $107 \%$ ) [48]. Considering the high potential of this technique for aroma recovery, in combination with other separation techniques or as an alternative, further research is worthwhile to investigate new synthesized and functionalized adsorbent materials which are also applicable in food industry for recovery of volatile aroma components. 


\section{Concluding Remarks}

Various techniques are proposed and tested according to studies reported in literature for recovery of aroma components, which all aim for minimizing the loss of aroma compounds and recovering the key components which are valuable in producing a high-quality final product. The technologies that can be applied for aroma recovery in food industry according to former investigations are stripping or distillation, which can be performed as membrane vacuum distillation or centrifugal distillation, pervaporation, supercritical extraction, and adsorption. Among these available techniques, stripping and distillation are widely applied for aroma recovery in processing alcoholic beverages and juices. Pervaporation as an alternative technique could show promising achievements for recovery of the aroma compounds from aqueous food streams. The current research focus on the application of this technique on aroma recovery is on the optimization of conditions to enhance the selectivity over specific aroma components in the process. In comparison to the other alternatives, less attention has been paid to supercritical extraction of aromas, specifically for aroma recovery from alcoholic beverages. The great selectivity of supercritical extraction has been proved by several investigators, which are demonstrative, since they fully take profit of applying supercritical fluid carbon dioxide as a non-toxic, and natural GRAS (Generally Recognized as safe) solvent with high selectivity at relatively low temperature, which prevents alteration of thermolabile products. Applying this technology, selectivity, and capacity can be tuned by changing operating pressure and temperature. Meanwhile, combining this technique with counter-current flow and reflux in a multistage contactor can lead to an optimized process conditions. Further research is recommended to study the application of this technique for recovery of aroma compounds, especially in alcoholic beverage industry which is of high economical interest, and where alcoholic beverage fractionation is a challenge, since ethanol is present at significant concentration in comparison to aroma components which are often present at trace levels and modifies the carbon dioxide solvent power in reducing its selectivity over water and other aroma products. Among the reviewed techniques, adsorption can be applied as a promising technique for selective recovery of aroma components and adding back the recovered key components to process streams, in order to produce a high-quality final product. Additional research is required to study the possibilities of applying this technique for flavor recovery as an alternative or combined with thermal processing.

Acknowledgements We would like to acknowledge ISPT (Institute for Sustainable Process Technology) for its financial support for the project with grant number (FO-10-05).
Open Access This article is distributed under the terms of the Creative Commons Attribution 4.0 International License (http:// creativecommons.org/licenses/by/4.0/), which permits unrestricted use, distribution, and reproduction in any medium, provided you give appropriate credit to the original author(s) and the source, provide a link to the Creative Commons license, and indicate if changes were made.

\section{References}

1. Abu-Zeid MAER, Zhang Y, Dong H, Zhang L, Chen H-L, Hou L (2015) A comprehensive review of vacuum membrane distillation technique. Desalination 356:1-14

2. Araujo WA, Alvarez MET, Wolf-Maciel MR (2008) Evaluation of pervaporation process for recovering a key orange juice flavour compound: modeling and simulation. Comput Aided Chem Eng 25:175-180

3. Aroujalian A, Raisi A (2007) Recovery of volatile aroma components from orange juice by pervaporation. J Membr Sci 303:154 161

4. Bagger-Jørgensen R, Meyer AS, Pinelo M, Varming C, Jonsson G (2011) Recovery of volatile fruit juice aroma compounds by membrane technology: sweeping gas versus vacuum membrane distillation. Innov Food Sci Emerg 12:388-397

5. Bagger-Jørgensen R, Meyer AS, Varming C, Jonsson G (2004) Recovery of volatile aroma compounds from black currant juice by vacuum membrane distillation. J Food Eng 64:23-31

6. Barcelo C, Gassiot M (1978) Determination of diacetyl in beer by gas chromatography with flame-ionization detection. J Chromatogr 147:463-469

7. Bejarano A, Del Valle JM (2017) Countercurrent fractionation of aqueous apple aroma constituents using supercritical carbon dioxide. J Supercrit Fluids 120:266-274

8. Bejarano A, Simoes PC, Del Valle JM (2016) Fractionation technologies for liquid mixtures using dense carbon dioxide. J Supercrit Fluids 107:321-348

9. Belisario-Sanchez YY, Taboada-Rodriguez A, Marin-Iniesta F, Lopez-Gomez A (2009) Dealcoholized wines by spinning cone column distillation: phenolic compounds and antioxidant activity measured by the 1,1 diphenyl-2-picrylhydrazyl method. J Agric Food Chem 57:6770-6778

10. BeverageMarketTrends (2015) Global alcoholic drinks market size, share, development, growth and demand forecast to 2020 industry insights by segment, by distribution channel and by geography. http://www.reportlinker.com/p03605424-summary/ Global-Alcoholic-Drinks-Market-Size-Share-DevelopmentGrowth-and-Demand-Forecast-to-Industry-Insights-by-SegmentBeer-Cider-FABs-by-Distribution-Channel-SupermarketsHypermarkets-Specialist-Retailers-On-premise-Others-and-byGeograph.html. Accessed 17 Feb 2017

11. Borjesson J, Karlsson HOE, Tragardh G (1996) Pervaporation of a model apple juice aroma solution comparison of membrane performance. J Membr Sci 119:229-239

12. Bourseau P, Masse A, Cros S, Vandanjon L, Jaouen P (2014) Recovery of aroma compounds from seafood cooking juices by membrane processes. J Food Eng 128:157-166

13. Branen AL, Davidson PM, Salminen S, Thorngate JH III (2002) Food Additives, 2nd edn. Dekker, M. Inc., Basel

14. Brazinha C, Crespo JG (2009) Aroma recovery from hydro alcoholic solutions by organophilic pervaporation: modeling of fractionation by condensation. J Membr Sci 341:109-121

15. Brunner G (2005) Supercritical fluids: technology and application to food processing. J Food Eng 67:21-33 
16. Carpine D, Dagostin LA, da Silva VR, Igarashi-Mafra L (2013) Adsorption of volatile aroma compound 2-phenyl ethanol from synthetic solution onto granular activated carbon in batch and continuous modes. J Food Eng 117:370-377

17. Catarino M, Ferreira A, Mendes A (2009) Study and optimization of aroma recovery from beer by pervaporation. J Membr Sci 341: $51-59$

18. Catarino M, Mendes A (2011) Dealcoholizing wine by membrane separation processes. Innov Food Sci Emerg 12:330-337

19. Catarino M, Mendez A (2011) Non-alcoholic beer-a new industrial process. Sep Purif Technol 79:342-351

20. ChemAxon https://www.chemaxon.com/. Accessed 16 Feb 2017

21. Chen G, Yang X, Wang R, Fane AG (2013) Performance enhancement and scaling control with gas bubbling in direct contact membrane distillation. Desalination 308:47-55

22. Cheng P-S (2016) Method of producing an aromatised food or beverage product

23. Cinelli G, Avino P, Notadonato I, Centola A, Russo MV (2014) Study of XAD-2 adsorbent for the enrichment of trace levels of phthalate esters in hydroalcoholic food beverages and analysis by gas chromatography coupled with flame ionization and ion-trap mass spectrometry detectors. Food Chem 146:181-187

24. Conetech (2016) http://www.conetech.com/. Accessed 23 Nov 2016

25. Da Porto C, Decorti D (2010) Countercurrent supercritical fluid extraction of grape-spirit. J Supercrit Fluids 55:128-131

26. Da Silva LF, Guerra CC, Klein D, Bergold AM (2017) Solid cation exchange phase to remove interfering anthocyanins in the analysis of other bioactive phenols in red wine. Food Chem 227: $158-165$

27. Da Silva Padilha CV, Miskinis GA, de Souza MEA O, Pereira GE, de Oliveira D, Bordignon-Luiz MT, dos Santos Lima M (2017) Rapid determination of flavonoids and phenolic acids in grape juices and wines by RP-HPLC/DAD: method validation and characterization of commercial products of the new Brazilian varieties of grape. Food Chem 228:106-115

28. Da Silva RPFF, Rocha-Santos TAP, Duarte AC (2016) Supercritical fluid extraction of bioactive compounds. Trends Anal Chem 76:40-51

29. Del Olmo Á, Blanco CA, Palacio L, Prádanos P, Hernández A (2014) Pervaporation methodology for improving alcohol-free beer quality through aroma recovery. J Food Eng 133:1-8. https://doi.org/10.1016/j.jfoodeng.2014.02.014

30. Del Valle JM (2015) Extration of natural compounds using supercritical $\mathrm{CO}$ 2: going from the laboratory to the industrial application. J Supercrit Fluids 96:180-199

31. Dellacassa E, Trenchs O, Farina L, Debernardis F, Perez G, Boido E, Carrau F (2017) Pineapple (Ananas comosus L. Merr.) wine production in Angola: characterization of volatile aroma compounds and yeast native flora. Int J Food Microbiol 241:161-167

32. Dias Canteli AM, Carpine D, de Paula Scheer A, Mafra MR (2014) Fixed-bed column adsorption of the coffee aroma compound benzaldehyde from aqueous solution onto granular activated carbon from coconut husk. LWT-Food Sci Technol 59:10251032

33. Diban N, Voinea OC, Urtiaga A, Ortiz I (2009) Vacuum membrane distillation of the main pear aroma compound: experimental study and mass transfer modeling. J Membr Sci 326:64-75. https://doi.org/10.1016/j.memsci.2008.09.024

34. Dongmo SN, Procopio S, Sacher B, Becker T (2016) Flavor of lactic acid fermented malt based beverages: current status and perspectives. Trends Food Sci Technol 54:37-51

35. Drioli E, Ali A, Macedonio F (2015) Membrane distillation: recent developments and perspectives. Desalination 356:56-84

36. Dulsat-Serra N, Quintanilla-Casas B, Vichi S (2016) Volatile thiols in coffee: a review on their formation, degradation, assessment and influence on coffee sensory quality. Food Res Int 89:982-988

37. Erten ES, Cadwallader KR (2017) Identification of predominant aroma components of raw, dry roasted and oil roasted almonds. Food Chem 217:244-253

38. Ferrarini R, Ciman GM, Camin F, Bandini S, Gostoli C (2016) Variation of oxygen isotopic ratio during wine dealcoholization by membrane contactors: experiments and modelling. J Membr Sci 498:385-394

39. Figoli A, Tagarelli A, Cavaliere B, Voci C, Sindona G, Sikdar SK, Drioli E (2009) Evaluation of pervapoartion process for kiwifruit juice by SPME-GC/ion trap mass spectrometry. Desalination 250: 1113-1117

40. Food additives, Ameliorating the flavors, Enriching the food. http://www.foodadditivesworld.com/flavorings.html. Accessed 9 Aug 2017

41. Garcia V, Diban N, Gorri D, Keiski R, Urtiaga A, Ortiz I (2008) Separation and concentration of bilberry impact aroma compound from dilute model solution by pervaporation. J Chem Technol Biotechnol 83:973-982

42. Gracia I, Rodriguez JF, Garcia MT, Alvarez A, Garcia A (2007) Isolation of aroma compounds from sugar cane spirits by supercritical CO2. J Supercrit Fluids 43:37-42

43. Guiochon G, Felinger A, Shirazi DG, Katti AM (2006) Fundamentals of preparative and nonlinear chromatography, 2nd edn. Elsevier Academic Press, San Diego

44. Hage DS, Cazes J (2005) Handbook of affinity chromatography, vol 92, 2nd edn. Taylor and Francis, Boca Raton

45. Hasanoğlu A, Rebolledo F, Plaza A, Torres A, Romero J (2012) Effect of the operating variables on the extraction and recovery of aroma compounds in an osmotic distillation process coupled to a vacuum membrane distillation system. J Food Eng 111:632-641. https://doi.org/10.1016/j.jfoodeng.2012.03.004

46. Heijman G, De Bruin WJ, Verhoeven MJ (2014) Process for the production of a liquid coffee concentrate. PCT/NL2012/050543

47. Isci A, Sahin S, Sumnu G (2006) Recovery of strawberry aroma compounds by pervaporation. J Food Eng 75:36-42

48. Jiang X, Cheng J, Zhou H, Li F, Wu W, Ding K (2015) Polyaniline-coated chitosan-functionalized magnetic nanoparticles: preparation for the extraction and analysis of endocrinedisrupting phenols in environmental water and juice samples. Talanta 141:239-246

49. Kalayioglu Z, Erim FB (2017) Total phenolic contents, antioxidant activities, and bioactive ingredients of juices from pomegranate cultivars worldwide. Food Chem 221:496-507

50. Karlsoon HOE, Loureiro S, Tragardh G (1995) Aroma compound recovery with pervaporation-temperature effects during pervaporation of a muscat wine. J Food Eng 26:177-191

51. Karlsoon HOE, Tragardh G (1996) Applications of pervapoartion in food processing. Trends Food Sci Technol 7:78-83

52. Karlsson HOE, Tragardh G (1997) Aroma recovery during beverage processing. J Food Eng 34:159-178

53. Kiralan M (2012) Volatile compounds of black cumin seeds (Nigella savita L.) from microwave-heating and conventional roasting. J Food Sci 77:481-484

54. Kupska M, Chmiel T, Jedrkiewicz R, EWardencki W, Namiesnik J (2014) Comprehensive two-dimensional gas chromatography for determination of the terpenes profile of blue honeysuckle berries. Food Chem 152:88-93

55. Lee LW, Tay GY, Cheong MW, Curran P, Yu B, Liu SQ (2017) Modulation of the volatile and non-volatile profiles of coffee fermented with Yarrowia lipolytica: I. Green coffee. LWT-Food Sci Technol 77:225-232

56. Lipzinki F, Olsson J, Tragardh G (2002) Scale-up of pervaporation for the recovery of natural aroma compounds in the food industry. Part1. Simulation and performance. J Food Eng 54:183-195 
57. Liu Q-R et al (2017) Preparation and stabilization behavior of octenyl succinic esters of soybean soluble polysaccharide in acidified milk beverages. Food Hydrocoll 63:421-428

58. Margallo M, Aldaco R, Barcelo A, Diban N, Ortiz I, Irabien A (2015) Life cycle assessment of technologies for partial dealcoholisation of wines. Sus Prod Consump 2:29-39

59. Marketresearch.com Global natural colors and flavors market, by types, applications and geography: Forecast up to 2017. MarketsandMarkets

60. Marketsandmarkets.com (2015) Food flavors market by type (chocolate, vanilla, fruits \& nuts, others), origin (natural, synthetic), application (beverages, savory \& snacks, bakery \& confectionery, dairy \& frozen products, others), \& by region-global forecast to 2020. www.marketsandmarkets.com/Market-Reports/ food-flavors-market-93115891.html. Accessed 16 Feb 2017

61. Maroulis ZB, Saravacos GD (2003) Food process design. Marcel Dekker Inc., New York

62. Martinez JL (2008) Supercritical fluid extraction of nutraceuticals and bioactive compounds. Taylor \& Francis Group, Boca Raton

63. Matias-Guiu P, Rodriguez-Bencomo JJ, Orriols I, Perez-Correa JR, Lopez F (2016) Floral aroma improvement of Muscat spirits by packed column distillation with variable internal reflux. Food Chem 213:40-48

64. Medina I, Martinez JL (1997) Dealcoholisation of cider by supercritical extraction with carbon dioxide. J Chem Tech Biotechnol 68:14-18

65. Mendez Sevillano D, Van der Wielen LAM, Hooshyar N, Ottens $\mathrm{M}$ (2014) Resin selection for the separation of caffeine from green tea catechins. Food Bioprod Process 92:192-198

66. Motta S, Guaita M, Petrozziello M, Ciambotti A, Panero L, Solomita M (2017) Comparison of the physichochemical and volatile composition of wine fractions obtained by two different dealcoholization techniques. Food Chem 221:1-10

67. Mottram DS (2007) The Maillard reaction: source of flavour in thermally processed foods. In: Berger RG (ed) Flavors and fragrances, Chemistry, Bioprocessing and Sustainability. SpringerVerlag, Berlin Heidelberg

68. Müller M, Bellut K, Tippmann J, Becker T (2016) Physikalische Verfahren zur Entalkoholisierung vershiedener Getränkematrizes und deren Einfluss auf qualitätsrelevante Merkmale. Chem Ing Tech 12:1911-1928

69. Nunez Montoya GA (2013) Development of a simulation tool for the economic optimization of an extraction plant for vegetable substrates using supercritical CO2. Pontificia Universidad Catolica de Chile

70. Olsson J, Tragardh G (1999) Influence of feed flow velocity on pervaporation aroma recovery from a model solution of apple juice aroma compounds. J Food Eng 39:107-115

71. Ottens M, Chilamkurthi S (2010) In: Rizvi S (ed) Separation, extraction and concentration processes in the food, beverage and neutraceutical industries. Woodhead Publishing series

72. Ottens M, Saffarionpour S, Noordman TR (2016) Method of producing beer having a tailored flavour profile. Patent EP3193632 (A1)

73. Pereira CC, Rufino JM, Habert AC, Nobrega R, Cabral LMC, Borges CP (2002) Membrane for processing tropical fruit juice. Desalination 148:57-60

74. Perrut M, Nunes Da Ponte M (1997) The extraction of aromas from fermented and distilled beverages. Proceedings of the 4th International Symposium on Supercritical fluids, ISBN 4925085-02-6 C:845

75. Pires EJ, Teixeira JA, Branyik T, Vicente AA (2014) Yeast: the soul of beer's aroma - a review of flavor-active esters and higher alcohols produced by the brewing yeast. Appl Microbiol Biotechnol 98:1937-1949
76. Plaza-Bolanos P, Frenich AG, Martinez Vidal JL (2010) Polycyclic aromatic hydrocarbons in food and beverages. Analytical methods and trends. J Chromatogr A 1217:6303-6326

77. Purwasasmita M, Kurnia D, Mandias FC, Khoiruddin, Wenten IG (2015) Beer dealcoholization using non-porous membrane distillation. Food Bioprod Process 94:180-186

78. Raisi A, Aroujalian A (2011) Aroma compound recovery by hydrophobic pervaporation: the effect of membrane thickness and coupling phenomena. Sep Purif Technol 82:53-62

79. Rao MA, Rizvi SSH, Datta AK, Ahmed J (2014) Engineering properties of foods, 4th edn. Taylor \& Francis Group LLC, Boca Raton

80. Rebecchi S, Pinelli D, Bertin L, Zama F, Fava F, Frascari D (2016) Volatile fatty acids recovery from the effluent of an acidogenic digestion process fed with grape pomace by adsorption on ion exchange resins. Chem Eng J 306:629-639

81. Reineccius G (2005) Flavor chemistry and technology, 2nd edn. Taylor \& Francis Group, LLC, Boca Raton

82. Ruiz-Rodriguez A et al (2012) Supercritical CO2 extraction applied toward the production of a functional beverage from wine. J Supercrit Fluids 61:92-100

83. Saffarionpour S, Mendez Sevillano D, Van der Wielen LA, Noordman T, Brouwer E, Ottens M (2016) Selective adsorption of flavor-active components on hydrophobic resins. J Chromatogr A $1476: 25-34$

84. Salgado CM, Fernández-Fernández E, Palacio L, Carmona FJ, Hernández A, Prádanos P (2017) Application of pervaporation and nanofiltration membrane processes for the elaboration of full flavored low alcohol white wines. Food Bioprod Process 101:11-21

85. Sanchez-Carmago AP, Mendiola JA, Ibanez E, Herrero M (2014) Supercritical fluid extraction. References Module in Chemistry, Mol Sci Chem Eng, Elsevier Inc. https://doi.org/10.1016/B9780-12-409547-2.10753-X

86. Saravacos G, Kostaropoulos AE (2016) Handbook of food processing equipment. Springer International Publishing, Switzerland

87. Schmidt-Traub H, Schulte M, Seidel-Morgenstern A (2012) Preparative chromatography, 2nd edn. John Wiley \& Sons, Hoboken

88. Schmidtke LM, Blackman JW, Agboola SO (2012) Production technologies for reduced alcoholic wines. J Food Sci 71:R25-R41

89. Schmitz Ongaratto R, Marmo do Nascimento Silva M, da Cunha Lage PL, Piacsek Borges C (2015) Extraction of aroma compounds of fruit juices by air stripping using a bubble column operating with antifoam and its effect on juice properties. J Food Eng 159:1-8

90. Señoráns FJ, Ruiz-Rodriguez A, Ibanez E, Tabera J, Reglero G (2003) Isolation of brandy aroma by countercurrent supercritical fluid extraction. J Supercrit Fluids 26:129-135

91. Shahidi F, Ambigaipalan P (2015) Phenolics and polyphenolics in foods, beverages and spices: antioxidant activity and health effects - a review. J Funct Foods 18:820-897

92. She M, Hwang ST (2006) Recovery of key aroma components from real flavour concentrates by pervaporation. J Membr Sci 279: 86-93

93. Silvestre WP, Agostini F, LAR M, Pauletti GF (2016) Fractionation of green mandarin(Citrus deliciosa Tenore) essential oil by vacuum fractional distillation. J Food Eng 178:90-94

94. Soni V, Abildskov J, Jonsson G, Gani R (2008) Modeling and analysis of vacuum membrane distillation for the recovery of volatile aroma compounds from black currant juice. J Membr Sci 320:442-455. https://doi.org/10.1016/j.memsci. 2008.04.025

95. Steen I, Waehrens SS, Petersen MA, Munchow M, Bredie WLP (2017) Influence of serving temperature on flavour perception and release of Bourbon Caturra coffee. Food Chem 219:61-68 
96. Suriyaphan O, Drake M, Chen XQ, Cadwallader KR (2001) Characteristic aroma components of British farmhouse cheddar cheese. J Agric Food Chem 49:1382-1387

97. Takacs L, Vatai G, Korany K (2007) Production of alcohol free wine by pervapoartion. J Food Eng 78:118-125

98. Tan J, Li R, Jiang Z-T (2014) Discrimination of fresh fruit juices by a fluorescent sensor array for carboxylic acids based on molecularly imprinted titania. Food Chem 165:35-41

99. Tang $\mathrm{N}$ et al (2016) High permeation flux polypropylene/ethylene vinyl acetate co-blending membranes via thermally induced phase separation for vacuum membrane distillation desalination. Desalination 394:44-55

100. Trabelsi D et al (2016) Supercritical extraction from Citrus aurantium amara peels using $\mathrm{CO} 2$ with ethanol as CO-solvent. J Supercrit Fluids 117:33-39

101. Valentas KJ, Rotstein E, Singh RP (1997) Handbook of food engineering practice. CRC Press LLC, Boca Raton

102. Verhoef A, Figoli A, Leen B, Bettens B, Drioli E, Van der Bruggen B (2008) Performance of a nanofiltration membrane for removal of ethanol from aqueous solutions by pervaporation. Sep Purif Technol 60:54-63

103. Victor-Ortega MD, Ochando-Pulido JM, Martinez-Ferez A (2016a) Phenols removal from industrial effluents through novel polymeric resins: kinetics and equilibrium studies. Sep Purif Technol 160:136-144

104. Victor-Ortega MD, Ochando-Pulido JM, Martnez-Ferez A (2016b) Performance and modeling of continuous ion exchnage processes for phenols recovery from olive mill wastewater. Process Saf Environ 100:242-251

105. Villanueva Bermejo D, Ibanez E, Reglero G, Fornari T (2016) Effect of cosolvents (ethyl lactate, ethyl acetate and ethanol) on the supercritical $\mathrm{CO} 2$ extraction of caffeine from green tea. $\mathrm{J}$ Supercrit Fluids 107:507-512

106. Wang J, JHuang S, Wang P, Yang Y (2016) Method development for the analysis of phthalate esters in tea beverages by ionic liquid hollow fibre liquid-phase microextraction and liquid chromatographic detection. Food Control 67:278-284

107. Weschenfelder TA, Lantin P, Viegas MC, de Castilhos F, Scheer AP (2015) Concentration of aroma compounds from an industrial solution of soluble coffee by pervaporation process. J Food Eng 159:57-65. https://doi.org/10.1016/j.jfoodeng.2015.03.018

108. Wylock C, Eloundou Mballa PP, Heilporn C, Debaste F, Fauconnier M-L (2015) Review on the potential technologies for aroma recovery from food industry flue gas. Trends Food Sci Technol 46:68-74

109. Yousuf A, Bonk F, Bastidas-Oyanedel J-R, Schmidt JE (2016) Recovery of carboxylic acids produced during dark fermentation of food waste by adsorption on Amberlite IRA-67 and activated carbon. Bioresour Technol 217:137-140

110. Zhou Q, Qian Y, Qian MC (2015) Analysis of volatile phenols in alcoholic beverages by ethylene glycol-polydimethylsiloxane based stir bar sorptive extraction and gas chromatography-mass spectrmetery. J Chromatogr A 1390:22-27 